higher in August, September, and October. The highest averages are in August, the maximum then being $35 \cdot 6^{\circ} \mathrm{C}$., the minimum $25^{\circ} \mathrm{C}$. $\left(77^{\circ} \mathrm{F}\right.$.). In point of personal experience, Ghardáqa is far more comfortable than Cairo in August, since every building is open to the breeze, and the wearing of coats, collars, and ties is not enforced.

The station is readily accessible, by land from Cairo, by sea from Suez. The former route involves a night in the train and an eight-hour journey by car across the desert and the Red Sea mountains, following the old road by which the Romans carried porphyry from their quarries in the mountains. From Suez the Anglo-Egyptian Oil Co.'s steamers sail three times a week, reaching Ghardáqa in 16 hours, and supply the oil camp with abundance of fresh water and provisions, so that the hardships of desert life are conspicuous by their absence.

It is hoped that the station will be complete in about a year's time, not only as regards laboratories, apparatus, machinery, and launch, but also with rest houses for research workers and students.

University of Egypt, Cyril Crossland. Cairo.

\section{Change of the Dielectric Constant of Nitrobenzene with Temperature.}

I HAVE made a study of the dielectric constant of nitrobenzene as a function of temperature, using a method depending on the beats of two high frequency oscillation circuits, as described by M. Wolfke and W. H. Keesom. ${ }^{1}$ Some details concerning the apparatus have been published already in a short note on the dielectric constant of ethyl ether. ${ }^{2}$

It should be stated that the temperature was determined with an error not exceeding $0.005^{\circ}$, and

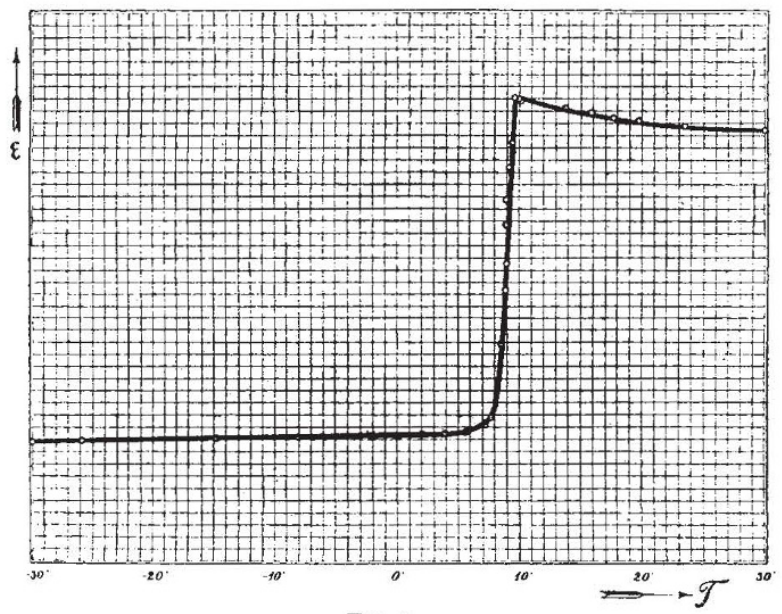

FIG. 1.

the changes in the fifth decimal of the value of the dielectric constant were still discernible.

The changes of the dielectric constant of nitrobenzene with temperature have been studied by Abegg and Seitz. ${ }^{3}$ These authors, however, used under-cooled liquid which was not purified sufficiently to obtain results with a very high degree of accuracy, as they themselves point out in their paper.

In my experiments the nitrobenzene was obtained from benzene crystals and was carefully purified by means of the most recent methods. It was afterwards fractionised five times at the interval of $0.05^{\circ} \mathrm{C}$.

The dielectric constant was studied through the

No. 3191, VoL. 126] temperature interval $-75^{\circ},+30^{\circ}$; special care being taken in the neighbourhood of the liquefaction point. The measurements were made both at increasing and decreasing temperatures.

With decrease of temperature the dielectric constant of nitrobenzene steadily increases from the value 35.4 at $30.01^{\circ}$ up to the maximum value 35.18 at $9 \cdot 6^{\circ}$, in the immediate neighbourhood of the solidifying point. A sharp decrease is then observed down to the value 11.82 at $7.713^{\circ}$, and then a slow asymptotic decrease down to the limiting value $9 \cdot 709$ at $-75^{\circ} \mathrm{C}$

These observed changes of dielectric constant of nitrobenzene with temperature do not agree with the results of Abegg and Seitz.

Some irregularities in the rate of change of the dielectric constant in the region of sharp decrease (that is, between $9.6^{\circ} \mathrm{C}$. and $7.713^{\circ} \mathrm{C}$.) suggest tho possibility of some complications in the neighbourhood of the solidifying point of nitrobenzene. A further study will be made to clear up this question.

The change of the dielectric constant of nitrobenzene at temperatures described above is represented on the accompanying graph (Fig. 1).

A full report of the investigations concerning ethyl ether and nitrobenzene will appear in the Comptes rendus des Sciences de la Soc. Polon. de Physique, Warsaw, and the Physikalische Zeitschrift.

Physical Laboratory,

Technical Institute, Warsaw, Nov. 13.

${ }^{1}$ Comm. Leiden, $190 a$.

p. 649 .

Ann.d. Phys., 60, $54 ; 1897$.

\section{Persian Science and Jundishapur.}

MAY I take the opportunity, afforded by the review in NATURE of Dec. 6 of Sir Percy Sykes's " History of Persia ", of directing attention to a point of interest to students of the history of science?

Readers of NATURE will be aware that what we call 'Arabic' science was to a very large extent the work of Persians who wrote in Arabic, though deriving from Greek, Syrian, and Hindu origins. It is also generally known that one of the greatest centres of Persian science was the school or university of Jundishapur. But there appears to be no general agreement as to where this school was situated; and I am hopeful that readers of NATURE may be able to throw some light on the matter. I give below some of the divergent views of authorities I have consulted. It will be noted that the name is spelt in a number of different ways, and, but for encroaching unduly on the space available I would accompany this letter with a plea that a little science should be applied to the transliteration of Oriental names.

Gibbon in his "Decline and Fall of the Roman Empire", chap. xlii., places Gondi Sapor near Susa. Browne in "History of Persian Literature ", vol. 1, p. 305, quotes from Carl Brockelmann to the effect that Jundi-Shapur was in Khuzistan, which does not conflict with Gibbon's statement. Sykes in his "History of Persia" (I have not yet seen the latest edition), vol. 1, p. 437, states that Gundisapur is the city of Shapur near Kazerun. This does not agree with the statement that it was in Khuzistan, which also has the support of the " Encyclopædia of Islam " under the heading 'Djundai-Sabur'. The "Encyclopædia Britannica", 10th ed., art. "Arabian Philosophy", refers to "Gandisapora or Nisabur in the east of Persia ", thus giving the city a third location. In the 11 th edition it is spelt "Junday Shapur " in the article on "Disful", and "Gundev-Shapur" in the article on "Shapur". Both articles place it near Susa. But in 